\title{
Dietary inflammatory index and inflammatory biomarkers in adolescents from LabMed physical activity study
}

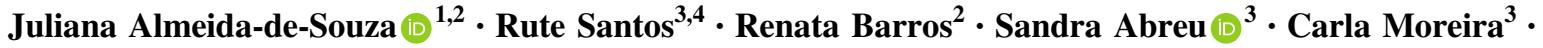 \\ Luís Lopes $\mathbb{1}^{3} \cdot$ Jorge Mota $^{3} \cdot$ Pedro Moreira ${ }^{2,5}$
}

Received: 23 November 2015 / Revised: 19 April 2017 / Accepted: 29 July 2017

(C) Macmillan Publishers Limited, part of Springer Nature 2017

\begin{abstract}
Background/objectives The dietary inflammatory index (DII) is a tool to measure the diet's inflammatory potential and has been used with adults to predict low-grade inflammation. The present study aims to assess whether this dietary score predicts low-grade inflammation in adolescents.

Subjects/methods The sample comprises 329 adolescents (55.9\% girls), aged 12-18 years, from LabMed Physical Activity Study. DII score was calculated based on a food-frequency questionnaire and categorized into tertiles. We collected blood samples to determine the follow inflammatory biomarkers: C-reactive protein (CRP), interleukin-6 (IL-6), complement component 3 (C3), and 4 (C4). In addition we calculated an overall inflammatory biomarker score. Odds ratios (OR) and $95 \%$ confidence intervals $(95 \% \mathrm{CI})$ were computed from binary logistic regression models.

Results DII score, comparing first with third tertile, was positively associated with IL-6 in crude model (OR $=1.88,95 \%$ CI:1.09-3.24, $\left.p_{\text {trend }}=0.011\right)$ and in fully adjusted (for biological and lifestyle variables) $(\mathrm{OR}=3.38,95 \% \mathrm{CI}: 1.24-9.20$, $\left.p_{\text {trend }}=0.023\right)$. Also, DII score was positively associated with $\mathrm{C} 4$, when fully adjusted (OR $=3.12,95 \% \mathrm{CI}: 1.21-8.10, p_{\text {trend }}$ $=0.016$ ). DII score was negatively associated with $\mathrm{C} 3$ in crude model, comparing first with second but not with third tertile, and no significant associations in fully adjusted model were observed, although a trend was found $(\mathrm{OR}=1.71,95 \%$ CI:0.63-4.66, $\left.p_{\text {trend }}=0.044\right)$. No significant associations were observed between DII score and CRP. However, DII score was positively associated with the overall inflammatory biomarker score, when fully adjusted $(\mathrm{OR}=5.61,95 \%$ CI:2.00-15.78, $p_{\text {trend }}=0.002$ ).
\end{abstract}

Conclusions DII score can be useful to assess the diet's inflammatory potential and its association with low-grade inflammation in adolescents.

Juliana Almeida-de-Souza

julianaalmeida@ipb.pt

1 School of Health, Polytechnic Institute of Bragança, Bragança, Portugal

2 Faculty of Nutrition and Food Sciences, University of Porto, Porto, Portugal

3 Research Centre in Physical Activity, Health and Leisure, Faculty of Sport, University of Porto, Porto, Portugal

4 Early Start Research Institute, University of Wollongong, Wollongong, NSW, Australia

5 Institute of Public Health, University of Porto, Porto, Portugal

\section{Introduction}

Low-grade inflammation correlates with a set of chronic conditions [1, 2] such as obesity [3], diabetes [3, 4], cardiovascular diseases [5, 6] and cancer [7, 8]. This association has also been found in youth for obesity [9-11], central obesity [12, 13], metabolic syndrome [14, 15], atherosclerosis [16], and several other cardiovascular risk factors $[10,13]$. In addition, systemic inflammation in childhood and adolescence is known to continue into adulthood [17].

Inflammatory status is heavily reliant on the measurement of the inflammatory biomarkers, such as acute phase proteins and cytokines [1], and a number of modifying factors, including diet, have been shown to influence the inflammatory status in the life cycle [1,2]. 
Studies about nutrition intake and low-grade inflammation in adolescents are scarce. However, evidence suggests that the consumption of fat and antioxidant vitamins (vitamins E, C and beta-carotene) are determinants of low-grade inflammation during adolescence [18]. While antioxidant vitamins $[19,20]$ and polyunsaturated fatty acids [19] seem to have anti-inflammatory properties, total fat [20] and saturated fat acids $[19,20]$ seem to be pro-inflammatory. Moreover, a Western dietary pattern is considered to be proinflammatory diet [19].

A dietary pattern approach has been considered advantageous because it considers synergistic or antagonistic interactions among nutrients and other food components [21]. The dietary inflammatory index (DII) $[22,23]$ is a score that attempts to combine the inflammatory property of each nutrient or food component of the diet.

The DII was designed by Cavicchia [22] and updated by Shivappa [23], and it is a tool to measure the diet's inflammatory power, scoring individuals' diets from maximal anti-inflammatory to maximal pro-inflammatory. This index was initially (in the first version) correlated to Creactive protein (CRP) in apparently healthy adults [22] and seniors [24] (in an adapted first version) and also to other inflammatory biomarkers such as interleukin-6 (IL-6) and a combined inflammatory biomarker score in adults and seniors [25]. For the updated version, several studies have found associations between DII score and CRP, in adults and seniors [26], and IL-6, tumour necrosis factor-alpha $(\mathrm{TNF}-\alpha)$ and another score of combined inflammatory biomarker in postmenopausal women [27]. The DII score has been used in several studies to predict mortality [28, 29], survival [30], and diseases, especially cancer [30, 31], but also obesity [32], cardiovascular disease [33] and metabolic syndrome [32, 34].

Considering that the published studies using the DII score were predominantly conducted with adults or seniors, and no study was found to focus on adolescents, this paper aims to assess the association between DII score and inflammatory biomarkers in adolescents.

\section{Subjects and methods}

\section{Study design and sampling}

We used baseline data, collected in 2011, from the Longitudinal Analysis of Biomarkers and Environmental Determinants of Physical Activity Study (LabMed Physical Activity Study). The LabMed Physical Activity Study is a school-based prospective cohort study carried out in five schools from the north of Portugal, which aimed to evaluate the independent and combined associations of dietary intake and fitness levels on blood pressure levels of adolescents.
The LabMed Physical Activity study was conducted in accordance with the World Medical Association's Helsinki Declaration for Human Studies. The Portuguese Data Protection Authority (\#1112434/2011), the Portuguese Ministry of Science and Education (0246200001/2011) and Faculty of Sport, University of Porto, approved the study. All participants were informed of the study's goals, and written informed consent was obtained from participating adolescents and their parents or guardians.

Considering combined healthy diet/physical activity pattern prevalence of $14 \%$ [35], we calculated a minimum sample size of 1086 subjects to have a power of $80 \%$, to detect a $15 \%$ difference between exposed and unexposed, at $5 \%$ significance, considering an expected dropout rate of about $20 \%$.

From an initial total sample of 1229 apparently healthy adolescents (12-18 years), 534 accepted to undergo blood collection. Of these, 412 adolescents had completed and accurate data on dietary intake. Of these, 329 adolescents had physical activity and sedentary time assessment with accelerometers. We found no differences in most variables between those who accepted or not to undergo blood sampling. However, boys, older and current smokers reject more undergoing blood sampling.

\section{Inflammatory biomarkers assessment and overall inflammatory biomarker score}

Blood samples were collected from the antecubital vein, at least $10 \mathrm{~h}$ of fasting conditions, refrigerated $\left(4-8^{\circ} \mathrm{C}\right)$, and sent to laboratory for measure inflammatory biomarkers: CRP by the latex-enhanced turbidimetric assay (Siemens Advia 1600/1800, Erlangen, Germany); IL- 6 by the chemiluminescence immunoassay (Immulite 2000, Diagnostic Products Corporation, Los Angeles, CA); complement component 3 (C3) and 4 (C4) by the Immunoturbidimetric assay (Siemens Advia 1600/1800, Erlangen, German).

Inflammatory biomarkers were dichotomized, based on sex- and age-adjusted median values, because they have a very skewed distribution, and no cut-offs values are established for adolescents. Categories considered were higher or lower inflammatory state. Medians of each category (lower/ higher) were defined as follows: $0.11 / 0.92 \mathrm{mg} / \mathrm{L}$ for CRP, $1.90 / 4.20 \mathrm{ng} / \mathrm{L}$ for $\mathrm{IL}-6,107.00 / 127.00 \mathrm{mg} / \mathrm{dL}$ for $\mathrm{C} 3$ and $17.00 / 25.55 \mathrm{mg} / \mathrm{dL}$ for $\mathrm{C} 4$.

We created an overall inflammatory biomarker score considering each biomarker categories, assigning one point to those who were above the sex, age-adjusted median or zero for those who were below, and summing all points assigned. The overall inflammatory biomarker score varies from zero to four inflammatory biomarkers above the median. We also create two categories: $0-1(49.9 \%)$ or $2-4$ $(50.1 \%)$ biomarkers above the median. 


\section{Physical activity and sedentary time assessment}

The physical activity and sedentary time were assessed with accelerometers GT1M (ActiGraph, Pensacola, Florida, USA). Participants were instructed to use the accelerometer attached on the right side of hip, with the notch faced upwards, over five consecutive days (3 weekdays, 2 weekend days) during waking hours and remove it during water-based activities. The epoch length was set to 2 $s$ to allow a more detailed estimate of physical activity intensity.

Accelerometer data were analysed by an automated data reduction program (ActivLive 6.12, ActiGraph, Pensacola, Florida, USA). Periods with $60 \mathrm{~min}$ of consecutive zeros were detected and flagged non-wear time. Participants had to have at least $8 \mathrm{~h}$ of data to count as a valid day and to have at least 3 valid days ( 2 weekdays, 1 weekend day) to be included. This combination of hours and days were studied to achieve a reliability of $90 \%$ [36].

After screening, the raw activity 'counts' were processed for determination of time spent in the different physical activity intensities. Physical activity was expressed as the time spent in moderate-to-vigorous physical activity. The cut-points recommend by American College of Sports Medicine [37] were used and we identify moderate-tovigorous physical activity and sedentary time was expressed in minutes.day ${ }^{-1}$.

\section{Dietary intake assessment}

A self-administered semi-quantitative food-frequency questionnaire validated for Portuguese population [38], and adapted to adolescents [39], was used to measure the dietary intake. The food-frequency questionnaire lists 91 options of food and beverage items or categories, and assesses the food habits in previous 12 months. For each option, there are nine response possibilities (from 'never or less than once per month' to 'six or more times per day'), standard portion sizes, and a seasonality choice. In the end, there is still space available for each respondent include any food not listed. Dietary intake estimation was made multiplying the portion size in grams by the multiple/fraction of daily frequency intake and by a seasonality variation factor for each option selected. The conversion, from food to energy and nutrients intake, was performed using The Food Processor Plus program version SQL (ESHA Research, Salem, OR, USA). This database was supplemented with the Portuguese food composition database [40].

To determine the misreporting of dietary assessment, implausible energy intake was calculated using the Goldberg's method, adapted by Black [41]. First, the basal metabolic rate was calculated using Schofield equation, considering sex and age. Second, a ratio energy intake/basal metabolic rate was compared to the $95 \%$ confidence limits (cut-offs). The cut-offs were calculated using our sample specific values for: mean of physical activity level, number of days of dietary assessment, within-subject coefficient of variation in energy intake, between-subject variation in physical activity, and variation in basal metabolism rate. The physical activity level was calculated in using counts. minutes $^{-1}$ and time of daily use from accelerometers, as Trost formula [42], reaching a value of 1.23. A number of 21 days of diet assessment was considered, as Black recommendation for food-frequency questionnaire [41]. The within-subject coefficient of variation in energy intake was calculated considering mean and standard deviation of energy intake in our sample. Between-subject variation in physical activity was calculated considering mean and standard deviation of physical activity level in our sample. A figure of $8.5 \%$ was used for the coefficient of variation of repeated basal metabolic rate measurements, as Black suggested [41]. The cut-offs calculated were 0.61-2.48; accordingly, a total of 150 adolescents with energy intake/ basal metabolic rate below 0.61 and over 2.48 were considered as misreporting of dietary assessment and were excluded.

Energy intake was expressed in kj.day ${ }^{-1}$ and kcal.day ${ }^{-1}$. Food-frequency questionnaire data was also used to calculate DII score.

\section{Description of the dietary inflammatory index score}

The DII is a literature-based tool [23] that measures the diet' inflammatory properties by a score, and it is based on review about the role of food and dietary constituents on the following inflammatory biomarkers: CRP, TNF- $\alpha$ and Interleukin's $1 \beta, 4,6$ and 10 . The review pointed 45 food parameters and they were scored with $+1,-1$ or 0 according to their inflammatory effects: pro, anti or null, respectively. The number of articles and the type of study were also used to weight each one of 45 food parameters and calculate a 'food parameter-specific overall inflammatory effect score', used as multiplying factors, to calculate a DII score. The final score, ranging from -8.87 to 7.98 , is interpreted as strongly anti-inflammatory to strongly proinflammatory, respectively.

In this study, the DII score was calculated considering 31 food parameters. Eugenol, garlic, ginger, saffron, turmeric, flavan-3-ol, flavones, flavonols, flavonones, anthocyanidis, isoflavones, pepper, thyme/oregano, rosemary were not included because no information was available for these components in the Food Processor nutritional database neither those herbs or spices were included in the foodfrequency questionnaire.

Briefly describing the DII score calculation according to Shivappa [23], first a mean and standard deviation were 
calculated for the 31 food parameters available (Table 1), because no global data for adolescent is available. Second, a $z$-score of each food parameter and for each participant was calculated. Third, the individual z-score were converted to a centred percentile. Fourth, each centred percentile were multiplied by its respective food parameter-specific overall inflammatory effect score, published by Shivappa [23], and the food parameter-specific DII score is obtained. Finally, the 31 food parameter-specific DII score was summed and an individual DII score was obtained. All food parameters are correlated $(p<0.001)$ with DII score; caffeine, alcohol and green/black tea are food parameters with weakest correlations; while magnesium, vitamin B6 and dietary fibre are food parameters with strongest correlations (Table 1).

Our DII score values ranged from -5.36 to 4.24 , and it was categorized, based on tertiles values, in accordance with Shivappa [26], considering Low (First tertile: < -1.34), Medium (Second tertile: -1.34 to 1.41 ) and High (Third tertile: $>1.41$ ) pro-inflammatory dietary property.

\section{Anthropometric assessment data}

Height and weight were measured with a portable stadiometer (SECA 213, Hamburg, Germany) and a portable scale (TANITA Inner Scan BC532, Tokyo, Japan), respectively. Adolescents should be standing upright, lightly dressed and no shoes. Body mass index was calculated from the weight $(\mathrm{kg})$ to height squared $\left(\mathrm{m}^{2}\right)$ ratio and participants were classified as underweight, normal weight, overweight and obese [43].

\section{Pubertal stage}

Pubertal stage, from 1 to 5 , was self-assessed relatively the secondary sex characteristics, according to Tanner and Whitehouse criteria [44].

\section{Socio-economic status}

Socio-economic status was self-assessed with Family Affluence Scale [45], ranking from 0 to 9, considering lower scores as lower socio-economic status.

\section{Smoking habits}

Smoking habits were self-reported and participants were classified according World Health Organization criteria [46] as: non-smokers, former smokers, occasional smokers and current smokers.
Table 1 Mean, standard deviation and correlation with final score of food parameters included in the calculation of DII score for the adolescents from LabMed physical activity study

\begin{tabular}{|c|c|c|c|}
\hline DII food parameters & Mean & SD & $r_{\mathrm{s}}^{\mathrm{a}}$ \\
\hline Alcohol (g/day) & 1.22 & 3.94 & -0.219 \\
\hline Vitamin B12 ( $\mu \mathrm{g} /$ day $)$ & 13.60 & 10.80 & -0.551 \\
\hline Vitamin B6 (mg/day) & 2.38 & 0.88 & -0.904 \\
\hline$\beta$-Carotene ( $\mu \mathrm{g} /$ day) & 1011.43 & 902.78 & -0.699 \\
\hline Caffeine (g/day) & 33.51 & 34.71 & -0.185 \\
\hline Carbohydrate (g/day) & 266.47 & 97.26 & -0.745 \\
\hline Cholesterol (mg/day) & 357.56 & 168.84 & -0.595 \\
\hline Energy (kcal/day) & 2127.72 & 680.98 & -0.809 \\
\hline Total fat (g/day) & 76.65 & 27.04 & -0.708 \\
\hline Fibre (g/day) & 21.85 & 10.18 & -0.903 \\
\hline Folic acid ( $\mu \mathrm{g} /$ day $)$ & 372.69 & 182.23 & -0.893 \\
\hline Green/black tea (g/day) & 17.20 & 42.51 & -0.263 \\
\hline Iron (mg/day) & 16.63 & 6.33 & -0.885 \\
\hline Magnesium (mg/day) & 331.71 & 119.47 & -0.919 \\
\hline Monounsaturated fatty acids (g/day) & 31.49 & 11.74 & -0.717 \\
\hline Niacin (mg/day) & 24.91 & 9.08 & -0.840 \\
\hline n-3 Fatty acids (g/day) & 1.40 & 0.61 & -0.793 \\
\hline n-6 Fatty acids (g/day) & 10.33 & 4.67 & -0.680 \\
\hline Onion (g/day) & 13.27 & 21.63 & -0.409 \\
\hline Protein (g/day) & 99.92 & 34.77 & -0.794 \\
\hline Polyunsaturated fatty acids (g/day) & 13.97 & 5.73 & -0.727 \\
\hline Riboflavin (mg/day) & 2.48 & 1.00 & -0.726 \\
\hline Saturated fat (g/day) & 24.60 & 8.84 & -0.580 \\
\hline Selenium (mg/day) & 102.87 & 39.99 & -0.827 \\
\hline Thiamin (mg/day) & 1.79 & 0.64 & -0.859 \\
\hline Trans fat (g/day) & 1.06 & 0.59 & -0.455 \\
\hline Vitamin A (RE/day) & 1237.95 & 1277.34 & -0.735 \\
\hline Vitamin C (mg/day) & 148.70 & 97.01 & -0.817 \\
\hline Vitamin D ( $\mu \mathrm{g} /$ day $)$ & 4.86 & 2.89 & -0.645 \\
\hline Vitamin E (mg/day) & 8.91 & 4.07 & -0.860 \\
\hline Zinc (mg/day) & 13.10 & 4.72 & -0.703 \\
\hline
\end{tabular}

$D I I$ dietary inflammatory index, $R E$ retinol equivalents, $S D$ standard deviation, $r_{\mathrm{s}}$ correlation

${ }^{a}$ correlation coefficients based on Spearman test

All $p<0.001$

\section{Statistical analyses}

Participants' characteristics are presented as percentages, medians and inter-quartiles range. Mann-Whitney $U$ test, Qui-square test and Spearman's correlation were used to assess associations between variables.

To study the association between DII score tertiles and inflammatory biomarkers, fifteen binary logistic regression models were constructed. There were three models (crude, sex-adjusted and fully adjusted) for each inflammation biomarker and for the overall inflammatory biomarker 
score, as dependent variables, and DII score tertiles, as predictor. Fully adjusted model were adjusted for sex, age, pubertal stage (Tanner A and B), body mass index, energy intake, socio-economic status, sedentary time, moderate-tovigorous physical activity and smoking habits. Multicollinearity was tested, and no multicollinearity between independent variables was observed. Post hoc power calculations were performed considering our sample size $(n=$ $329)$, our minimal odds ratio $(\mathrm{OR}=3.12)$, a null hypothesis value of 0.5 , and $5 \%$ significance, achieving a power of 0.99 .

A 0.05 level of significance and 95\%CI (confidence interval) were considered. Data was analysed using the statistical package SPSS $®$, version 21.0 (SPSS Inc., Chicago, IL, USA) and power were calculated using G*power, version 3.1 (Faul, Erdfelder, Lang, \& Buchner, 2007).

\section{Results}

Girls presented on average a lower CRP than boys and no significant differences were observed for other inflammatory biomarker and DII score (Table 2).

The IL-6 was positively associated with DII score and adolescents within the third tertile of the DII score had higher prevalence of higher IL- 6 than adolescents within the first or second tertiles. However, adolescents within first tertile of the DII score had higher prevalence of higher C3. No significant differences were observed for the other biomarkers or for the overall inflammatory biomarker score and DII score, neither significant correlations were observed between any inflammatory biomarkers or the overall inflammatory biomarker and score DII score when this variables were continuously treated (Table 3).

Table 4 shows for fully adjusted models that adolescents within the third tertile of the DII score showed significantly higher odds of having higher IL-6 (OR $=3.38,95 \%$ CI:1.24-9.20, $\left.\quad p_{\text {trend }}=0.023\right), \quad \mathrm{C} 4 \quad(\mathrm{OR}=3.12, \quad 95 \%$ $\left.\mathrm{CI}: 1.21-8.10, p_{\text {trend }}=0.016\right)$, and the overall inflammatory biomarker score $\left(\mathrm{OR}=5.61,95 \% \mathrm{CI}: 2.00-15.78, \mathrm{p}_{\text {trend }}=\right.$ 0.002).

\section{Discussion}

To the best of our knowledge, this is the first study exploring associations between the DII score and inflammatory biomarkers in adolescents.

We showed that DII score predicted low-grade inflammation, specifically IL-6, C4 and the overall inflammatory biomarker score, in adolescents. In our study, the DII score was independently and positively associated with IL-6, and adolescents whose diets showed low- or medium- inflammatory properties had a lower prevalence of higher IL-6. Also, in the fully adjusted regression model, when comparing DII score of the first tertile (low-inflammatory diet) with the third tertile (high-inflammatory diet), the odds of having higher IL- 6 was about three times higher. These findings seem to be important since IL-6 is considered a more sensitive indicator of cardiovascular disease than others like CRP [47, 48].

In our study, DII score was not associated with CRP, contrary to what we were expecting considering the DII scores conception (a literature-based tool about the role of diet on inflammatory biomarkers, including CRP) [22, 23] and validation $[22,26]$, but consistent with other studies in adults [25, 27]. However, some studies have found this relationship, particularly those conducted with apparently healthy adults [22, 26, 34], or seniors [24]. In this regard, it is important to notice that in these studies, the CRP mean levels were much higher than in our sample. For example, in the SEASONS cohort [26], CRP mean ranged from 2.2 \pm 5.1 to $2.2 \pm 5.7 \mathrm{mg} / \mathrm{L}$ in women and from $2.3 \pm 4.4$ to 2.4 $\pm 4.6 \mathrm{mg} / \mathrm{L}$ in men, whereas in our study, the corresponding values were $0.83 \pm 2.24 \mathrm{mg} / \mathrm{L}$ (girls) and $1.62 \pm 4.54 \mathrm{mg} / \mathrm{L}$ (boys). Moreover, only $7 \%$ of the participants in our study presented CRP levels between 3 and $10 \mathrm{mg} / \mathrm{L}$, while in the SEASONS cohort, this prevalence reached $18 \%$. Another important concept to be noted is the number of modifying factors related to the inflammatory biomarkers such as age or body fatness [1, 2]. Again comparing our study to the SEASONS cohort [26], our age range is 12-18 years, while the SEASONS cohort is 20-70 years; by contrast, our prevalence of normal BMI is about $65 \%$ (girls) and $68 \%$ (boys), while the SEASONS cohort was about $44 \%$ (women) and $30 \%$ (men). Thus, with all of these parameters described, differences in the prevalence of CRP inadequacy and the presence of modifying factors of inflammatory biomarkers between samples may help to explain the differences in the association between DII score and CRP across the studies.

We also found an association between the DII score with $\mathrm{C} 4$ and the overall inflammatory biomarker score, in line with some authors [25, 27] who found a relationship between DII score and a different inflammatory biomarker scores only for the fully adjusted model. This means that adolescents with a high pro-inflammatory diet have an odds ratio five times higher of having two to four biomarkers above the median. However, these associations are true only for the fully adjusted model. Calder et al. [1] discussed how modifying factors can affect the concentration of inflammatory biomarkers, and we tried to control the effect of most of the possible variables in the fully adjusted models, such as age and pubertal stage; body mass index as a measurement of body fatness; sedentary time and moderateto-vigorous physical activity as measurements of physical 
Table 2 Participants' characteristics according to sex in adolescents from the LabMed physical activity study

\begin{tabular}{|c|c|c|c|c|c|}
\hline & & $\operatorname{All}^{\mathrm{a}}(n=329)$ & $\operatorname{Girls}^{\mathrm{a}}(n=184)$ & Boys $^{\mathrm{a}}(n=145)$ & $p^{\mathrm{b}}$ \\
\hline DII score & & $\begin{array}{l}0.57 \\
(-0.92-2.07)\end{array}$ & $\begin{array}{l}0.63 \\
(-0.82-2.24)\end{array}$ & $\begin{array}{l}0.37 \\
(-1.26-1.78)\end{array}$ & 0.120 \\
\hline Age (years) & & $15.0(13.0-16.0)$ & $15.0(13.0-16.0)$ & $14.0(13.0-15.0)$ & 0.447 \\
\hline \multirow{4}{*}{$\begin{array}{l}\text { Pubertal stage: Tanner } \\
\mathrm{A}^{\mathrm{c}}\end{array}$} & 2 & $8.2 \%$ & $3.3 \%$ & $14.5 \%$ & $<0.001$ \\
\hline & 3 & $34.3 \%$ & $28.3 \%$ & $42.1 \%$ & \\
\hline & 4 & $45.3 \%$ & $55.4 \%$ & $32.4 \%$ & \\
\hline & 5 & $12.2 \%$ & $13.00 \%$ & $11.00 \%$ & \\
\hline \multirow{4}{*}{$\begin{array}{l}\text { Pubertal stage: Tanner } \\
\mathrm{B}^{\mathrm{c}}\end{array}$} & 2 & $7.9 \%$ & $2.7 \%$ & $14.5 \%$ & $<0.001$ \\
\hline & 3 & $21.3 \%$ & $19.6 \%$ & $23.4 \%$ & \\
\hline & 4 & $50.2 \%$ & $48.9 \%$ & $51.7 \%$ & \\
\hline & 5 & $20.7 \%$ & $28.8 \%$ & $10.3 \%$ & \\
\hline \multirow[t]{4}{*}{ Body mass index } & underweight & $3.00 \%$ & $2.2 \%$ & $4.1 \%$ & 0.715 \\
\hline & normal weight & $66.3 \%$ & $66.3 \%$ & $66.2 \%$ & \\
\hline & overweight & $22.8 \%$ & $22.8 \%$ & $22.8 \%$ & \\
\hline & obese & $7.9 \%$ & $8.7 \%$ & $6.9 \%$ & \\
\hline Socio-economic status & & $6.0(5.0-8.0)$ & $6.5(6.0-8.0)$ & $6.0(5.0-8.0)$ & 0.479 \\
\hline \multirow[t]{2}{*}{ Energy intake } & $\left(\mathrm{kj} \mathrm{day}^{-1}\right)$ & $\begin{array}{l}8648(6734-10 \\
609)\end{array}$ & $\begin{array}{l}8501(6567-10 \\
061)\end{array}$ & $\begin{array}{l}8818(6916-11 \\
190)\end{array}$ & 0.038 \\
\hline & $\left(\right.$ kcal.day $\left.^{-1}\right)$ & $\begin{array}{l}2059\left(\begin{array}{l}1 \\
526\end{array}\right) \\
\end{array}$ & $\begin{array}{l}2024(1564-2 \\
395)\end{array}$ & $\begin{array}{l}2100(1647-2 \\
664)\end{array}$ & \\
\hline $\begin{array}{l}\text { Sedentary behaviour } \\
\left(\text { minutes.day }{ }^{-1}\right)\end{array}$ & & $\begin{array}{l}667.4 \\
(619.4-725.3)\end{array}$ & $\begin{array}{l}678.4 \\
(632.8-734.1)\end{array}$ & $\begin{array}{l}645.9 \\
(607.5-713.2)\end{array}$ & 0.003 \\
\hline $\begin{array}{l}\text { Moderate-to-vigorous } \\
\text { physical activity } \\
\text { (minutes.day }^{-1} \text { ) }\end{array}$ & & $51.0(39.1-65.3)$ & $45.5(35.1-59.5)$ & $56.7(43.0-71.5)$ & $<0.001$ \\
\hline \multirow[t]{4}{*}{ Smoking habits ${ }^{\mathrm{d}}$} & $\begin{array}{l}\text { Current } \\
\text { smokers }\end{array}$ & $1.2 \%$ & $1.1 \%$ & $1.4 \%$ & \\
\hline & $\begin{array}{l}\text { Occasional } \\
\text { smokers }\end{array}$ & $0.9 \%$ & $1.1 \%$ & $0.7 \%$ & \\
\hline & $\begin{array}{l}\text { Former } \\
\text { smokers }\end{array}$ & $5.8 \%$ & $3.8 \%$ & $8.3 \%$ & \\
\hline & Non-smokers & $92.1 \%$ & $94.0 \%$ & $89.7 \%$ & \\
\hline $\mathrm{CRP}(\mathrm{mg} / \mathrm{L})$ & & $0.20(0.11-0.77)$ & $0.11(0.11-0.49)$ & $0.34(0.11-1.26)$ & $<0.001$ \\
\hline IL-6 (ng/L) & & $1.90(1.90-3.00)$ & $1.90(1.90-3.40)$ & $1.90(1.90-3.35)$ & 0.268 \\
\hline $\mathrm{C} 3(\mathrm{mg} / \mathrm{dL})$ & & $\begin{array}{l}116.0 \\
(107.0-126.0)\end{array}$ & $\begin{array}{l}119.0 \\
(107.0-127.0)\end{array}$ & $\begin{array}{l}115.0 \\
(106.5-126.0)\end{array}$ & 0.179 \\
\hline $\mathrm{C} 4$ (mg/dL) & & $20.0(16.0-24.0)$ & $20.0(16.0-25.0)$ & $20.0(17.0-24.0)$ & 0.587 \\
\hline $\begin{array}{l}\text { Overall inflammatory } \\
\text { biomarkers score }^{\mathrm{e}}\end{array}$ & & $\begin{array}{l}0.57 \\
(-0.92-2.07)\end{array}$ & $\begin{array}{l}0.63 \\
(-0.82-2.24)\end{array}$ & $\begin{array}{l}0.37 \\
(-1.26-1.78)\end{array}$ & 0.476 \\
\hline
\end{tabular}

DII dietary inflammatory index, $C R P$ C-reactive protein, $I L-6$ interleukin-6, C3 complement component 3, $C 4$ complement component 4

${ }^{a}$ The data shown in percentage for categorical variables and median (interquartile range) for continuous variables

${ }^{\mathrm{b}} P$-value was calculated based on Qui-squared test for categorical variables and Mann-Whitney $\mathrm{U}$ test for continuous variables

${ }^{\mathrm{c}}$ Tanner A indicates development stages of breast in girls and genitalia (penis size and testicular volume) in boys; Tanner B indicates development stages of public hair distribution (Tanner B)

${ }^{\mathrm{d}}$ Qui-squared test performed with 'Current smokers' and 'Occasional smokers' together to improve power of test

${ }^{\mathrm{e}}$ Overall inflammatory biomarkers score were designed calculating an age and gender adjusted $z$-score for each inflammatory biomarker (CRP, IL-

$6, \mathrm{C} 3$ and $\mathrm{C} 4$ ) and summing them 
Table 3 Differences and correlations between inflammatory biomarkers and DII in adolescents from the LabMed physical activity study

\begin{tabular}{|c|c|c|c|c|c|c|c|c|}
\hline & & & \multicolumn{6}{|c|}{ DII score } \\
\hline & & & \multicolumn{2}{|c|}{ Continuous } & \multicolumn{3}{|c|}{ Tertiles-inflammatory property } & \multirow[t]{2}{*}{$p^{\mathrm{b}}$} \\
\hline & & & $r_{\mathrm{s}}$ & $p^{\mathrm{a}}$ & $\begin{array}{l}\text { First } \\
- \text { Low }(< \\
-1.34)\end{array}$ & $\begin{array}{l}\text { Second } \\
\text {-Medium } \\
(-1.34 \text { to } 1.41)\end{array}$ & $\begin{array}{l}\text { Third } \\
\text {-High } \\
(>1.41)\end{array}$ & \\
\hline \multirow[t]{3}{*}{ CRP } & Continuos & & -0.089 & 0.109 & & & & \\
\hline & Categories & Lower & & & $54.3 \%$ & $51.7 \%$ & $54.3 \%$ & 0.900 \\
\hline & & Higher & & & $45.7 \%$ & $48.3 \%$ & $45.7 \%$ & \\
\hline \multirow[t]{3}{*}{ IL-6 } & Continuos & & 0.096 & 0.083 & & & & \\
\hline & Categories & Lower & & & $71.4 \%$ & $69.9 \%$ & $56.9 \%$ & 0.046 \\
\hline & & Higher & & & $28.6 \%$ & $30.1 \%$ & $43.1 \%$ & \\
\hline \multirow[t]{3}{*}{$\mathrm{C} 3$} & Continuos & & 0.004 & 0.939 & & & & \\
\hline & Categories & Lower & & & $40.0 \%$ & $58.0 \%$ & $51.7 \%$ & 0.047 \\
\hline & & Higher & & & $60.0 \%$ & $42.0 \%$ & $48.3 \%$ & \\
\hline \multirow[t]{3}{*}{$\mathrm{C} 4$} & Continuos & & 0.006 & 0.919 & & & & \\
\hline & Categories & Lower & & & $52.9 \%$ & $57.3 \%$ & $45.7 \%$ & 0.174 \\
\hline & & Higher & & & $47.1 \%$ & $42.7 \%$ & $54.3 \%$ & \\
\hline \multirow{3}{*}{$\begin{array}{l}\text { Overall } \\
\text { inflammatory } \\
\text { biomarkers score }^{c}\end{array}$} & Continuos & & 0.016 & 0.528 & & & & \\
\hline & Categories & Lower & & & $44.3 \%$ & $47.6 \%$ & $37.9 \%$ & 0.296 \\
\hline & & Higher & & & $55.7 \%$ & $52.4 \%$ & $62.1 \%$ & \\
\hline
\end{tabular}

DII dietary inflammatory index, $C R P$ C-reactive protein, $I L-6$ interleukin-6, $C 3$ complement component 3 , C4 complement component 4

${ }^{a} P$-values and $r_{\mathrm{s}}$ coefficients were based on Spearman test

${ }^{\mathrm{b}} P$-values were based on Qui-square test

${ }^{c}$ Overall inflammatory biomarkers score were designed summing the inflammatory biomarkers (CRP, IL-6, $\mathrm{C} 3$ and $\mathrm{C} 4)$ categories, wherein for each category was assigned one point if the biomarker was above the median adjusted by age and sex or zero if below the median (in)activity; sex, smoking habits and socio-economic status. These factors together must have a significant impact on inflammatory biomarkers, masking the association between DII score with $\mathrm{C} 4$ and with the overall inflammatory biomarker score in the crude models. However, when we control those variables, the association between DII score with $\mathrm{C} 4$ and the overall inflammatory biomarker score can be observed.

The association between C3 biomarker and DII score is unclear. While C3 was independently and negatively associated with the DII score and adolescents whose diets showed medium-inflammatory properties had a lower prevalence of higher $\mathrm{C} 3$ then adolescents whose diets showed low-inflammatory properties; in the fully adjusted regression model, no association was found although the trend was significant. Confounding factors are probably the source of controversy. It is known that higher concentrations of $\mathrm{C} 3$ in adolescents have been linked to high body fatness [12, 49] and, in fact, we found an association between body mass index with $\mathrm{C} 3(\mathrm{OR}=1.31,95 \%$ :
1.21-1.42, $p<0.0001$; data not shown) in our fully adjusted model.

Moreover we found an association between DII score and the overall inflammatory biomarker score in fully adjusted model, but not for CRP or $\mathrm{C} 3$, although the trend is significant for $\mathrm{C} 3$. Furthermore, the overall inflammatory biomarker score had showed a higher odds ratio $(\mathrm{OR}=$ 5.61) than IL-6 $(\mathrm{OR}=3.38)$ or $\mathrm{C} 3(\mathrm{OR}=3.12)$. In fact, the inflammatory biomarkers in general are considered nonspecific pro-inflammatory response markers in healthy people, and the biomarkers' signatures that best represent low-grade inflammation are yet to be fully understood [2]. Our overall inflammatory biomarker score is a more complex and integrated assessment of low-grade inflammation, rather than just an inflammatory biomarker alone. This score takes into account the sums of the effects of all inflammatory biomarkers, that is, those that were shown to have a relationship with the DII (IL-6 and C4) and those that did not (CRP and C3), and it seems to represent better low-grade inflammation in this group of adolescents. 
Table 4 Association between DII score tertiles and inflammatory biomarkers categories among adolescents from LabMed physical activity study

\begin{tabular}{|c|c|c|c|c|}
\hline & \multicolumn{4}{|c|}{ DII score: OR $(95 \% \mathrm{CI})$} \\
\hline & $\begin{array}{l}\text { First tertile } \\
\text { Low }(<-1.34)\end{array}$ & $\begin{array}{l}\text { Second tertile } \\
\text { Medium }(-1.34 \text { to } 1.41)\end{array}$ & $\begin{array}{l}\text { Third Tertile } \\
\text { High }(>1.41)\end{array}$ & $p_{\text {trend }}$ \\
\hline \multicolumn{5}{|l|}{ CRP models } \\
\hline Crude & 1.00 & $1.11(0.62-1.96)$ & $1.00(0.55-1.81)$ & 0.900 \\
\hline Sex-adjusted & 1.00 & $1.11(0.63-1.97)$ & $1.02(0.56-1.86)$ & 0.914 \\
\hline Fully-adjusted $^{\mathrm{a}}$ & 1.00 & $1.71(0.83-3.51)$ & $2.33(0.88-6.20)$ & 0.230 \\
\hline \multicolumn{5}{|l|}{ IL-6 models } \\
\hline Crude & 1.00 & $1.08(0.57-2.02)$ & $1.89(1.00-3.58)$ & 0.048 \\
\hline Sex-adjusted & 1.00 & $1.07(0.57-2.01)$ & $1.82(0.96-3.45)$ & 0.071 \\
\hline Fully-adjusted $^{\mathrm{a}}$ & 1.00 & $1.44(0.68-3.08)$ & $3.38(1.24-9.20)$ & 0.023 \\
\hline \multicolumn{5}{|l|}{ C3 models } \\
\hline Crude & 1.00 & $0.48(0.27-0.86)$ & $0.62(0.34-1.14)$ & 0.049 \\
\hline Sex-adjusted & 1.00 & $0.48(0.27-0.86)$ & $0.61(0.33-1.12)$ & 0.047 \\
\hline Fully-adjusted $^{\mathrm{a}}$ & 1.00 & $0.75(0.36-1.57)$ & $1.71(0.63-4.66)$ & 0.044 \\
\hline \multicolumn{5}{|l|}{ C4 models } \\
\hline Crude & 1.00 & $0.83(0.47-1.48)$ & $1.33(0.74-2.42)$ & 0.175 \\
\hline Sex-adjusted & 1.00 & $0.83(0.47-1.45)$ & $1.32(0.73-2.40)$ & 0.189 \\
\hline Fully-adjusted $^{\mathrm{a}}$ & 1.00 & $1.13(0.57-2.28)$ & $3.12(1.21-8.10)$ & 0.016 \\
\hline \multicolumn{5}{|c|}{ Overall inflammatory biomarkers score models ${ }^{\mathrm{b}}$} \\
\hline Crude & 1.00 & $0.88(0.49-1.56)$ & $1.30(0.71-2.38)$ & 0.297 \\
\hline Sex-adjusted & 1.00 & $0.88(0.49-1.56)$ & $1.30(0.71-2.38)$ & 0.304 \\
\hline Fully-adjusted $^{\mathrm{a}}$ & 1.00 & $1.75(0.84-3.66)$ & $5.61(2.00-15.78)$ & 0.002 \\
\hline
\end{tabular}

OR odds ratio, $C I$ confidence interval, DII dietary inflammatory index, CRP C-reactive protein, IL-6 interleukin-6, C3 complement component 3, C4 complement component 4

${ }^{a}$ All fully adjusted model were adjusted for sex, age, pubertal stage-Tanner A and B, body mass index, energy intake, socio-economic status, sedentary behaviour, moderate-to-vigorous physical activity and smoking habits

${ }^{\mathrm{b}}$ Overall inflammatory biomarkers score were designed summing the inflammatory biomarkers (CRP, IL-6, $\mathrm{C} 3$ and $\mathrm{C} 4)$ categories, wherein for each category was assigned one point if the biomarker was above the median adjusted by age and sex or zero if below the median
The strengths of this study include the novelty of its aim and the use of objectively measured physical activity and sedentary time. We also included sedentary time as a covariate in our models once it was considered a risk factor for cardiovascular health independently of physical activity levels [50]. In addition, we used only accurate food-frequency questionnaires, according to Goldberg's method [41]. This method is useful to evaluate the mean population bias in reporting energy intake and recommends the use of information about physical activity, as we did. Moreover, our models considered other important potential confounders such as age, body mass index, sex and smoking, considering them as modifying factors that affect the inflammatory biomarker concentration $[1,2]$.

This study is not without limitations. First, due to lack of cut-offs established for inflammatory biomarkers, we used median values age- and sex-adjusted. For IL-6, we considered 1.9ng/L (1.9-6.95ng/L) for most age/sex group. Nevertheless, our cut-offs are very close to those reported by the Asklepios Study (1.6ng/L for IL-6) [51], where authors also found an association between DII score and IL6. For CRP, our cut-offs $(0.11-0.79 \mathrm{mg} / \mathrm{dL})$ are close to that reported by Visser $(0.22 \mathrm{mg} / \mathrm{dL})$ [11], reporting a positive association with overweight in children and adolescents. Second, we used inflammatory biomarkers considered nonspecificity in order to measure low-grade inflammation in healthy subjects $[1,2]$; however, we attempted to overcome this with adjusted models and the overall inflammatory biomarker score. Third, we calculated the DII score using only 31 out of a possible 45 food parameters because only these components are present in our database. Thus, DII score in our sample has a lower range $(-5.36$ to 4.02$)$ than the original possible ranges $(-8.87$ to 7.98$)$ [23]. However, it represents $56 \%$ of the score range and is similar to the SEASONS cohort (57\%) [26]. 
In summary, DII score was associated with IL-6, C4 and the overall inflammatory biomarker score after adjustments for biological and lifestyle characteristics. DII score was not associated with CRP and C3 in Portuguese adolescents.

DII score can be useful to assess the diet's inflammatory properties and its association with low-grade inflammation in adolescents.

Acknowledgements The authors gratefully acknowledged the participation of all adolescents and their parents, teachers and schools of the LabMed and Physical Activity Study, the cooperation of volunteer's, the Department of Hygiene and Epidemiology (University of Porto) for the conversion food frequency questionnaire data into nutrients, and the Research Centre in Physical Activity, Health and Leisure (University of Porto) for the sponsoring the LabMed and Physical Activity Study.

Competing interests The authors declare that they have no competing interests.

\section{References}

1. Calder PC, Ahluwalia N, Albers R, Bosco N, Bourdet-Sicard R, Haller D, et al. A consideration of biomarkers to be used for evaluation of inflammation in human nutritional studies. Br J Nutr. 2013;109(Suppl 1):34 https://doi.org/10.1017/ s0007114512005119. S1. e-pub ahead of print 2013/02/01

2. Minihane AM, Vinoy S, Russell WR, Baka A, Roche HM, Tuohy $\mathrm{KM}$, et al. Low-grade inflammation, diet composition and health: current research evidence and its translation. Br J Nutr. 2015; 114(7):999-1012. https://doi.org/10.1017/s0007114515002093. e-pub ahead of print 2015/08/01

3. van Greevenbroek MM, Schalkwijk CG, Stehouwer CD. Obesityassociated low-grade inflammation in type 2 diabetes mellitus: causes and consequences. Neth J Med. 2013;71(4):174-87. e-pub ahead of print 2013/06/01

4. Spranger J, Kroke A, Mohlig M, Hoffmann K, Bergmann MM, Ristow $\mathrm{M}$, et al. Inflammatory cytokines and the risk to develop type 2 diabetes: results of the prospective population-based European Prospective Investigation into Cancer and Nutrition (EPIC)Potsdam Study. Diabetes. 2003;52(3):812-7. e-pub ahead of print 2003/02/28

5. Berg AH, Scherer PE. Adipose tissue, inflammation, and cardiovascular disease. Circ Res. 2005;96(9):939-49. https://doi. org/10.1161/01.res.0000163635.62927.34. e-pub ahead of print 2005/05/14

6. Libby P. History of discovery: Inflammation in Atherosclerosis. Arterioscler Thromb Vasc Biol. 2012;32(9):2045-51. https://doi. org/10.1161/ATVBAHA.108.179705

7. Fernandes JV, Cobucci RN, Jatoba CA, Fernandes TA, de Azevedo JW, de Araujo JM. The role of the mediators of inflammation in cancer development. Pathol Oncol Res. 2015;21 (3):527-34. https://doi.org/10.1007/s12253-015-9913-z. e-pub ahead of print 2015/03/06

8. Ostan R, Lanzarini C, Pini E, Scurti M, Vianello D, Bertarelli C, et al. Inflammaging and cancer: a challenge for the Mediterranean diet. Nutrients. 2015;7(4):2589-621. https://doi.org/10.3390/ nu7042589. e-pub ahead of print 2015/04/11.

9. Ford ES, Galuska DA, Gillespie C, Will JC, Giles WH, Dietz WH. $\mathrm{C}$-reactive protein and body mass index in children: findings from the Third National Health and Nutrition Examination Survey,
1988-94. J Pediatr. 2001;138(4):486-92. https://doi.org/10.1067/ mpd.2001.112898. e-pub ahead of print 2001/04/11

10. Lambert M, Delvin EE, Paradis G, O'Loughlin J, Hanley JA, Levy E. C-reactive protein and features of the metabolic syndrome in a population-based sample of children and adolescents. Clin Chem. 2004;50(10):1762-8. https://doi.org/10.1373/clinchem. 2004.036418. e-pub ahead of print 2004/08/17

11. Visser M, Bouter LM, McQuillan GM, Wener MH, Harris TB. Low-grade systemic inflammation in overweight children. Pediatrics. 2001;107(1):E13. e-pub ahead of print 2001/01/03

12. Warnberg J, Nova E, Moreno LA, Romeo J, Mesana MI, Ruiz JR, et al. Inflammatory proteins are related to total and abdominal adiposity in a healthy adolescent population: the AVENA Study. Am J Clin Nutr. 2006;84(3):505-12. e-pub ahead of print 2006/ 09/09

13. Galcheva SV, Iotova VM, Yotov YT, Bernasconi S, Street ME. Circulating proinflammatory peptides related to abdominal adiposity and cardiometabolic risk factors in healthy prepubertal children. Eur J Endocrinol. 2011;164(4):553-8. https://doi.org/10. 1530/eje-10-1124. e-pub ahead of print 2011/01/13

14. Ford ES, Ajani UA, Mokdad AH. The metabolic syndrome and concentrations of C-reactive protein among U.S. youth. Diabetes care. 2005;28(4):878-81. e-pub ahead of print 2005/03/29

15. de Ferranti SD, Gauvreau K, Ludwig DS, Newburger JW, Rifai N. Inflammation and changes in metabolic syndrome abnormalities in US adolescents: findings from the 1988-94 and 1999-2000 National Health and Nutrition Examination Surveys. Clin Chem. 2006;52(7):1325-30. https://doi.org/10.1373/clinchem.2006. 067181. e-pub ahead of print 2006/05/06

16. Jarvisalo MJ, Harmoinen A, Hakanen M, Paakkunainen U, Viikari $\mathrm{J}$, Hartiala J, et al. Elevated serum C-reactive protein levels and early arterial changes in healthy children. Arterioscler Thromb Vasc Biol. 2002;22(8):1323-8. e-pub ahead of print 2002/08/13

17. Juonala M, Magnussen CG, Berenson GS, Venn A, Burns TL, Sabin MA, et al. Childhood adiposity, adult adiposity, and cardiovascular risk factors. N Engl J Med. 2011;365(20):1876-85. https://doi.org/10.1056/NEJMoa1010112. e-pub ahead of print 2011/11/18

18. Zimmermann MB, Aeberli I. Dietary determinants of subclinical inflammation, dyslipidemia and components of the metabolic syndrome in overweight children: a review. Int J Obes. 2008;32 (Suppl 6):S11-18. https://doi.org/10.1038/ijo.2008.202. e-pub ahead of print 2008/12/23

19. Del Mar Bibiloni M, Maffeis C, Llompart I, Pons A, Tur JA. Dietary factors associated with subclinical inflammation among girls. Eur J Clin Nutr. 2013;67(12):1264-70. https://doi.org/10. 1038/ejen.2013.196. e-pub ahead of print 2013/10/24

20. Aeberli I, Molinari L, Spinas G, Lehmann R, l'Allemand D, Zimmermann MB. Dietary intakes of fat and antioxidant vitamins are predictors of subclinical inflammation in overweight Swiss children. Am J Clin Nutr. 2006;84(4):748-55. e-pub ahead of print 2006/10/07

21. Barbaresko J, Koch M, Schulze MB, Nothlings U. Dietary pattern analysis and biomarkers of low-grade inflammation: a systematic literature review. Nutr Rev. 2013;71(8):511-27. https://doi.org/10. 1111/nure.12035. e-pub ahead of print 2013/07/20

22. Cavicchia PP, Steck SE, Hurley TG, Hussey JR, Ma Y, Ockene IS, et al. A new dietary inflammatory index predicts interval changes in serum high-sensitivity C-reactive protein. J Nutr. 2009;139(12):2365-72. https://doi.org/10.3945/jn.109.114025. epub ahead of print 2009/10/30

23. Shivappa N, Steck SE, Hurley TG, Hussey JR, Hebert JR. Designing and developing a literature-derived, population-based dietary inflammatory index. Pub Health Nutr. 2014;17 (8):1689-96. https://doi.org/10.1017/s1368980013002115. e-pub ahead of print 2013/08/15 
24. Xu H, Sjogren P, Arnlov J, Banerjee T, Cederholm T, Riserus U, et al. A proinflammatory diet is associated with systemic inflammation and reduced kidney function in elderly adults. J Nutr. 2015;145(4):729-35. https://doi.org/10.3945/jn.114.205187. epub ahead of print 2015/04/04

25. van Woudenbergh GJ, Theofylaktopoulou D, Kuijsten A, Ferreira I, van Greevenbroek MM, van der Kallen CJ, et al. Adapted dietary inflammatory index and its association with a summary score for low-grade inflammation and markers of glucose metabolism: the Cohort study on Diabetes and Atherosclerosis Maastricht (CODAM) and the Hoorn study. Am J Clin Nutr. 2013;98 (6):1533-42. https://doi.org/10.3945/ajcn.112.056333. e-pub ahead of print 2013/10/25

26. Shivappa N, Steck SE, Hurley TG, Hussey JR, Ma Y, Ockene IS, et al. A population-based dietary inflammatory index predicts levels of C-reactive protein in the Seasonal Variation of Blood Cholesterol Study (SEASONS). Pub Health Nutr. 2014;17 (8):1825-33. https://doi.org/10.1017/s1368980013002565. e-pub ahead of print 2013/10/11

27. Tabung FK, Steck SE, Zhang J, Ma Y, Liese AD, Agalliu I et al. Construct validation of the dietary inflammatory index among postmenopausal women. Ann Epidemiol 2015; https://doi.org/10. 1016/j.annepidem.2015.03.009; e-pub ahead of print 2015/04/23

28. Shivappa N, Blair CK, Prizment AE, Jacobs DR, Jr., Steck SE, Hebert JR. Association between inflammatory potential of diet and mortality in the Iowa Women's Health study. Eur J Nutr. 2015; https://doi.org/10.1007/s00394-015-0967-1; e-pub ahead of print 2015/07/02

29. Shivappa N, Harris H, Wolk A, Hebert JR. Association between inflammatory potential of diet and mortality among women in the Swedish Mammography Cohort. Eur J Nutr. 2015. https://doi.org/ 10.1007/s00394-015-1005-z. e-pub ahead of print 2015/08/01

30. Galas A, Kulig J. Low-grade dietary-related inflammation and survival after colorectal cancer surgery. J Cancer Res Clin Oncol. 2014;140(9):1517-25. https://doi.org/10.1007/s00432-014-17116. e-pub ahead of print 2014/05/28

31. Wirth MD, Shivappa N, Steck SE, Hurley TG, Hebert JR. The dietary inflammatory index is associated with colorectal cancer in the National Institutes of health-American Association of Retired Persons Diet and Health Study. Br J Nutr 2015;1-9; https://doi.org/ 10.1017/s000711451500104x; e-pub ahead of print 2015/04/15

32. Ruiz-Canela M, Zazpe I, Shivappa N, Hebert JR, Sanchez-Tainta A, Corella D, et al. Dietary inflammatory index and anthropometric measures of obesity in a population sample at high cardiovascular risk from the PREDIMED (PREvencion con DIeta MEDiterranea) trial. Br J Nutr. 2015;113(6):984-95. https://doi.org/10.1017/ s0007114514004401. e-pub ahead of print 2015/02/28

33. Garcia-Arellano A, Ramallal R, Ruiz-Canela M, Salas-Salvado J, Corella D, Shivappa N, et al. Dietary Inflammatory Index and Incidence of Cardiovascular Disease in the PREDIMED Study. Nutrients. 2015;7(6):4124-38. https://doi.org/10.3390/ nu7064124. e-pub ahead of print 2015/06/04.

34. Wirth MD, Burch J, Shivappa N, Violanti JM, Burchfiel CM, Fekedulegn D, et al. Association of a dietary inflammatory index with inflammatory indices and metabolic syndrome among police officers. J Occup Environ Med. 2014;56(9):986-9. https://doi.org/ 10.1097/jom.0000000000000213. e-pub ahead of print 2014/07/22

35. Huh J, Riggs NR, Spruijt-Metz D, Chou CP, Huang Z, Pentz M. Identifying patterns of eating and physical activity in children: a latent class analysis of obesity risk. Obesity. 2011;19(3):652-8. https://doi.org/10.1038/oby.2010.228. e-pub ahead of print 2010/ $10 / 12$

36. Rich C, Geraci M, Griffiths L, Sera F, Dezateux C, Cortina-Borja M. Quality Control Methods in Accelerometer Data Processing:
Defining Minimum Wear Time. PloS ONE. 2013;8(6):e67206 https://doi.org/10.1371/journal.pone.0067206

37. Trost SG, Loprinzi PD, Moore R, Pfeiffer KA. Comparison of accelerometer cut points for predicting activity intensity in youth. Med Sci Sports Exerc. 2011;43(7):1360-8. https://doi.org/10. 1249/MSS.0b013e318206476e. e-pub ahead of print 2010/12/07

38. Lopes C, Aro A, Azevedo A, Ramos E, Barros H. Intake and adipose tissue composition of fatty acids and risk of myocardial infarction in a male Portuguese community sample. J Am Diet Assoc. 2007;107(2):276-86. https://doi.org/10.1016/j.jada.2006. 11.008. e-pub ahead of print 2007/01/30

39. Silva D, Rego C, Guerra A. Characterization of food habits and comparative study between two methods of food assessment in adolescents. Rev Aliment Humana. 2004;10:33-40.

40. Martins I, Porto A, Luísa O. Table Composition of Foods. Lisbon, Portugal: National Institute of Health Dr Ricardo Jorge; 2006.

41. Black AE. Critical evaluation of energy intake using the Goldberg cut-off for energy intake:basal metabolic rate. A practical guide to its calculation, use and limitations. Int J Obes Relat Metab Disord J Int Assoc Study Obes. 2000;24(9):1119-30. e-pub ahead of print 2000/10/18

42. Trost SG, Ward DS, Moorehead SM, Watson PD, Riner W, Burke JR. Validity of the computer science and applications (CSA) activity monitor in children. Med Sci Sports Exerc. 1998;30 (4):629-33. e-pub ahead of print 1998/05/05

43. Cole TJ, Lobstein T. Extended international (IOTF) body mass index cut-offs for thinness, overweight and obesity. Pediatr Obes. 2012;7(4):284-94. https://doi.org/10.1111/j.2047-6310.2012. 00064.x. e-pub ahead of print 2012/06/21

44. Tanner JM, Whitehouse RH. Clinical longitudinal standards for height, weight, height velocity, weight velocity, and stages of puberty. Arch Dis Child. 1976;51(3):170-9. e-pub ahead of print 1976/03/01

45. Currie C, Molcho M, Boyce W, Holstein B, Torsheim T, Richter $M$. Researching health inequalities in adolescents: the development of the Health Behaviour in School-Aged Children (HBSC) family affluence scale. Soc Sci Med. 2008;66(6):1429-36. https://doi.org/ 10.1016/j.socscimed.2007.11.024. e-pub ahead of print 2008/01/09

46. World Health Organization. Guidelines for Controlling and Monitoring the Tobacco Epidemic. Geneva: World Health Organization; 1998.

47. Ridker PM, Rifai N, Stampfer MJ, Hennekens CH. Plasma concentration of interleukin- 6 and the risk of future myocardial infarction among apparently healthy men. Circulation. 2000;101 (15):1767-72. e-pub ahead of print 2000/04/19

48. Cesari M, Penninx BW, Newman AB, Kritchevsky SB, Nicklas $\mathrm{BJ}$, Sutton-Tyrrell K, et al. Inflammatory markers and onset of cardiovascular events: results from the Health $\mathrm{ABC}$ study. Circulation. 2003;108(19):2317-22. https://doi.org/10.1161/01.cir. 0000097109.90783.fc. e-pub ahead of print 2003/10/22

49. Oliveira-Santos J, Santos R, Moreira C, Abreu S, Lopes L, Agostinis C, et al. Ability of Measures of Adiposity in Identifying Adverse Levels of Inflammatory and Metabolic Markers in Adolescents. Childhood Obes. 2016;12(2):135-43. https://doi.org/ 10.1089/chi.2015.0124. e-pub ahead of print 2016/01/30.

50. Tremblay MS, Colley RC, Saunders TJ, Healy GN, Owen N. Physiological and health implications of a sedentary lifestyle. Appl Physiol Nutr Metab. 2010;35(6):725-40. https://doi.org/10. 1139/h10-079. e-pub ahead of print 2010/12/18

51. Shivappa N, Hebert JR, Rietzschel ER, De Buyzere ML, Langlois $\mathrm{M}$, Debruyne E, et al. Associations between dietary inflammatory index and inflammatory markers in the Asklepios Study. Br J Nutr. 2015;113(4):665-71. https://doi.org/10.1017/ s000711451400395x. e-pub ahead of print 2015/02/03 